\title{
EFFECT OF WIND-STRUCTURE INTERACTION ON LONGITUDINAL RESPONSE OF TALL BUILDINGS
}

\author{
Professor Dr. Sorush Niknamian \\ Board Member of Weston A Price Foundation, Washington DC, USA \\ Wmail: so.niknamian@gmail.com
}

\begin{abstract}
Since rapid population growth leads to tall-buildings construction, several studies are conducted regarding effective parameters on tall-structures behavior against wind pressure, which indicate wind speed changes, structures' damping and environmental context density are effective on structure's aerodynamic and aerostatic behavior. Accordingly, using CFD, CSD and CARRC, we investigated impact of mentioned factors on structure-wind interaction. Here, several 3D standard models were generated using ABAQUS software, next, wind profile was modeled in atmospheric boundary layer, flow turbulence was simulated by LES method and simulation method was used to transfer non-uniform loads from fluid to structural nodes. Structural damping was also determined by Rayleigh-method. Results show that structures without damping have much higher responses to wind. Furthermore, denser contexts around the structure change wind velocity profile at height and increase maximum displacements and stresses in upper and lower parts; average wind pressure distribution in high-rise buildings is influenced by average wind speed.
\end{abstract}

Keywords: CAARC tall building, Computational Fluid Dynamics (CFD), Aerodynamic analysis, Aeroelastic analysis

\section{INTRODUCTION}

In current societies, due to rapid growth of large cities' population, space constraints, as well as socioeconomic factors, tall-buildings construction has been grown considerably. This has caused important consequences for different aspects of human life, such as urban weather conditions, the environment, health conditions and safety (Tamura, 2009). According to the mentioned issues, the study and analysis of tall structures under the wind pressure influence is necessary to ensure the safety and well-being of cities' residents (Elshaer et al., 2017). For example, pressure and suction caused by wind in various aspects of high-rise structures is an effective parameter in architectural and structural design of high-rise buildings (Huang, 2017; Cao et al., 2009). The pressure and suction resulted from the wind is a kind of random loading that depends on various parameters, such as structural shape, structural dimensions, environmental density, wind potentials and architectural and structural characteristics of the building (Lin et al., 2005).

Computational Wind Engineering (CWE) is one of the most important applications in Computational Fluid Dynamics (CFD), in which special numerical models are designed to simulate wind effects on urban structures, such as long bridges and tall buildings. The CFD method is able to provide information from all parts of the structure, compared to in-site structural measurement method and wind tunnel method. In addition, in this method, real-size structures can be modeled. The CFD's most important advantage is its capability to carry out parametric studies such as changing the environmental context conditions, shape and size of the structure, mechanical properties of the structure and impacts of the wind on the wind-structure interaction (Tominaga et al., 2008). Therefore, CFD can be considered as a suitable method for evaluation of wind effect on structures. Plenty of numerical researches on the aerodynamics of structures have been carried out since the early 1980s. One of the first articles devoted to numerical simulation of the wind effects on objects was presented by Hirt et al. (1978). In their work, the finite difference model was applied to the aerodynamics of windy objects. Hanson et al. (1986) and Summers et al. (1986) can also be considered as the first researchers who performed numerical simulation of the building's aerodynamics. Subsequently, many analytical studies were conducted to evaluate the effective parameters on the structures' behavior against wind. Meng et al. (2018) examined the effect of the building's corners shape on the building's aerodynamic performance. Using CFD method, Elshaer et al. (2017) also investigated effect of increasing the buildings' density in vicinity of the structure on the wind pressure imported on building. Mou et al., (2017) and Zhao and He (2017) numerically investigated the impact of wind pressure on rectangular and oval structures. Montazeri and Blocken (2013) carried out studies on 
CAARC structures using CFD simulation to investigate effect of wind turbulence and wind speed on structures. From other studies conducted to investigate effect of wind on structures using analytical works and CFD simulation, following works can be pointed: an investigation on impact of hurricanes on the pressure and force coefficients of prismatic and dome structures (Yousef et al., 2018), investigation of the desired structural environmental impacts, the rate of urban texture density and layout of surrounding buildings (regular or irregular) (Abdi and Bitsuamlak, 2016) and investigation of wind pressure created in irregular structures on the plan (Chakraborty and Dalui, 2014).

In this research, aerodynamic and aero-elastic analyzes were carried out to evaluate effect of wind speed, structural damping and density of area surrounding the structure on the wind-structure interaction. Here, the modeling of the CAARC standard building and CFD simulation were implemented by the finite elements software ABAQUS and then few wind cases were applied with different velocities on structures with and without damping and different environmental density conditions. Co-simulation method was used to transfer non-uniform loads from fluid to structural nodes. Using the results of nonlinear analysis, effect of changing these parameters on the wind pressure coefficient, aerodynamic behavior and aero-elastic behavior of the structure was investigated, as well.

\section{FUNDAMENTAL EQUATIONS AND NUMERICAL METHODS}

\section{Numerical model for simulation of wind flow}

The basic equations of fluids consider the above assumptions which are intended to simplify the relations and equations, and are expressed in simplified equations of Navier-Stokes and so on (Lateb et al., 2013). The Wilirin's descriptive relations are used for simulation of the fluids' aerodynamic behavior. Also, numerical problems in the corresponding calculations of fluids flow turbulence can be eliminated using Large Eddy Simulation (LES) (Smagorinsky, 1963).

The fundamental equations are addressed as follows (Alminhanaa et al., 2018):

$$
\begin{aligned}
& \frac{\partial \mathrm{v}_{\mathrm{i}}}{\partial t}+\mathrm{v}_{\mathrm{j}} \frac{\partial \mathrm{v}_{\mathrm{i}}}{\partial \mathrm{x}_{\mathrm{j}}} \delta_{\mathrm{ij}}=-\frac{1}{\rho} \frac{\partial p}{\mathrm{x}_{\mathrm{j}}} \delta_{\mathrm{ij}}+\frac{\theta}{\mathrm{x}_{\mathrm{j}}}\left[\frac{\mu+\mu_{\mathrm{t}}}{\rho}\left(\frac{\partial \mathrm{v}_{\mathrm{i}}}{\partial \mathrm{x}_{\mathrm{j}}}+\frac{\partial \mathrm{v}_{\mathrm{j}}}{\partial \mathrm{x}_{\mathrm{i}}}\right)+\frac{\lambda}{\rho} \frac{\partial \mathrm{v}_{\mathrm{k}}}{\partial \mathrm{x}_{\mathrm{k}}} \delta_{\mathrm{ij}}\right] \quad \mathrm{i} . \mathrm{j} . \mathrm{k}=1.2 .3 \text { in } \Omega^{\mathrm{f}} \\
& \frac{\partial p}{\partial t}+\mathrm{v}_{\mathrm{j}} \frac{\partial p}{\partial \mathrm{x}_{\mathrm{j}}}+\rho \mathrm{c}^{2} \frac{\partial \mathrm{v}_{\mathrm{j}}}{\partial \mathrm{x}_{\mathrm{i}}}=0 \quad \mathrm{j}=1.2 .3 \text { in } \Omega^{\mathrm{f}}
\end{aligned}
$$

Where, $v_{i}$ is velocity vector component; $\delta_{i j}$ is Kronecker delta function component; $\mu$ and $\lambda$ are fluid's volumetric and dynamic viscosity, respectively; $\mu_{t}$ is eddy viscosity; $p$ is thermodynamic pressure; $\rho$ is the fluid's specific volume; $c$ is sound velocity inside the fluid and $\Omega^{f}$ is the fluid's spatial domain limited by boundary conditions (Alminhanaa et al., 2018).

\section{A numerical model for dynamics simulation of a building}

Structural reaction of buildings affected by wind is determined using wind tunnel testing through hard or flexible methods. On the other hand, high-rise buildings are known as thin structures with low primary natural frequency (usually less than $1 \mathrm{~Hz}$ ). Therefore, these structures may be subject to high displacements in the direction of the wind (longitudinal direction) or in the direction of the transverse flow of wind.

In order to discuss dynamic methods, D'Alembert's force is written in the general equilibrium equation. The volumetric force at a point, $f$, can be written in the form of a difference in the applied external volumetric force, $F$, and a D'Alembert's force:

$f=F-\rho \ddot{u}$

Where, $\rho$ is the materials' current density at desired point and $u$ is the point displacement. The finite elements approximation for the equation of equilibrium is expressed as follows:

$M^{N M} \ddot{u}^{M}+I^{N}-P^{N}=0$

Where, $\mathrm{M}^{\mathrm{MN}}$ is consistent mass matrix, $\mathrm{I}^{\mathrm{N}}$ and $\mathrm{P}^{\mathrm{N}}$ are respectively the internal and external force vectors 


\section{Geometry and Mechanical Properties of the model}

The CAARC's standard tall building model was presented in 1969 with the dimensions of $182.88 * 45.72 *$ $30.48 \mathrm{~m}$ for assessment and deriving the results reliable and consistent with experimental tests (Wardlaw and Moss, 1970). Although a structure can be modeled with real size in numerical modeling cases, the analysis time can be lowered by decreasing the size and number of mesh networks (Elshaer et al., 2017). In present study, the CAARC standard tall building with a scale of $\frac{1}{250}$, (i.e. dimensions of $0.1232 * 0.1822 * 0.7355 \mathrm{~m}$ ) was modeled by the finite elements software ABAQUS. In Fig 1, the geometric properties and boundary conditions of the modeled sample are shown in the software. The mechanical properties of the structure are presented in Table 1.

Table 1. Mechanical properties of the structure

\begin{tabular}{cc}
\hline Specific mass- $\boldsymbol{\rho}$ & $\mathbf{1 6 0} \mathbf{~ k g} / \mathbf{m}^{\mathbf{3}}$ \\
\hline Natural frequency- $n$ & $\mathbf{0 . 2}$ \\
\hline Young modulus- $E$ & $\mathbf{2 . 3 \times 1 0 ^ { 8 }} \mathbf{~ k g} / \mathbf{c m}^{\mathbf{2}}$ \\
\hline Poisson ratio- - & $\mathbf{0 . 2 5}$ \\
\hline Damping ratio- $\zeta$ & $\mathbf{1 \%}$ \\
\hline
\end{tabular}

Table 2. Mechanical properties of the fluid (wind)

\begin{tabular}{|c|c|}
\hline Specific mass- $\rho$ & $\begin{array}{l}1.225 \\
\mathrm{~kg} / \mathrm{m}^{3}\end{array}$ \\
\hline Dynamic viscosity- $\mu$ & $1.825 \times 10^{-5}$ \\
\hline Volumetric viscosity- $\lambda$ & $\mathbf{0}$ \\
\hline Reference velocity(Inflow at $\mathrm{Z}=182.88)-V_{H}$ & $12.80 \mathrm{~m} / \mathrm{s}$ \\
\hline Characteristic dimension(Width)- $W$ & 0.18m \\
\hline
\end{tabular}
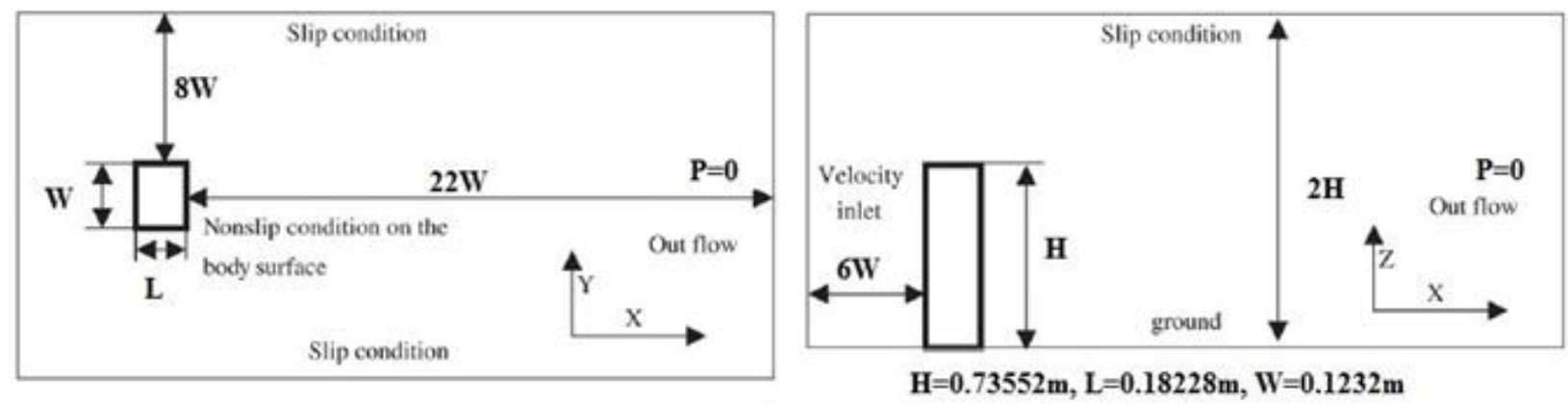

Fig 1. Geometric properties and boundary conditions of the modeled sample

\section{Modeling of wind flow and boundary conditions}

Since the CAARC structure is considered as a very tall structure, the wind profile used to represent the wind flow in the atmospheric boundary conditions is presented in Equation (5) (AIJ, 1996):

$\frac{U(z)}{U_{H}}=\left(\frac{Z}{z_{H}}\right)^{a}$

In this equation, $\mathrm{U}(\mathrm{z})$ is the wind speed at the height $\mathrm{Z}$ and $\mathrm{U}_{\mathrm{H}}$ is the wind speed is at the upper height of the structure, namely, at $182.88 \mathrm{~m}$ equal to $12.7 \mathrm{~m} / \mathrm{s}$. The coefficient $\alpha$ is also the wind profile coefficient, which is 0.28 based on the AIJ guideline for loads imported on the building (Hübner et al., 2014).The mechanical 
properties of the fluid (wind) are also presented in Table 2. These constants lead to creation of a Reynolds number of 156575.

\section{Meshing}

As mentioned above, the CAARC's standard tall building was used which had been modeled as a simple cubic. For gridding of this structure, 2220 regular eight-node hexahedron elements called C3D8R and 2926 nodes were used. Dimensions of grids in the adapted model are $0.018 \times 0.019 \times 0.02$. These dimensions and number of grids created on the validated model were derived upon several trials and errors as long as elimination of sensitivity of the analytical results to the extent of meshes.

For gridding of the wind range, 497,000 regular eight-node hexahedron elements called FC3D8 and 519,726 nodes were used. Dimensions of grids in the adapted model are variable The grid is as fine and isotropic as possible in order to achieve desirable turbulence accuracy in all directions, preserving the turbulence properties which are quickly destroyed by large-coarse grids. Figure 2 illustrates gridding of the structure and the wind range.
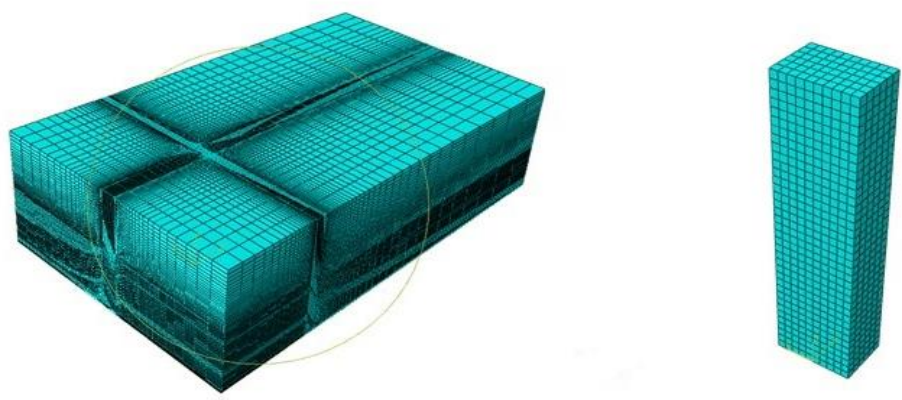

Fig 2. Gridding, A) CAARC standard tall building, B) wind range

\section{Fluid-structure interaction}

In the numerical simulations of Fluid Structure Interaction (FSI) problems, coupling scheme plays a major role. In the FSI analysis, mechanical equilibrium and kinematic continuity should be met on the boundaries between different physical parts, which are performed using numerical coupling algorithms. Studies by Felippa et al., (2001), Zhang and Hisada (20004) show that the connectivity algorithms are classified either as integrated or grid-based. Integrated algorithms use a single system of governing equations to analyze an FSI problem, and the grid-based algorithm leads to an independent solution in each physical sector. Since integrated models are inefficient computationally while working with CWE, a coupling scheme was used in present work.

The software ABAQUS uses internal methods to solve multiphase simulations. This coupling method is used to simulate FSI. Abaqus/Standard can be coupled with Abaqus/CFD, so that such data as fluid pressure on the structure is transmitted in a coordinated manner between Abaqus/CFD and Abaqus/Standard (ABAQUS User's Manual, V. 6.16.1.).

\section{Analysis of numerical model and validation}

In the generated numerical model analysis, some aerodynamic parameters were used to describe behavior of the CAARC tall building model. These parameters include wind pressure coefficient $\left(C_{\mathrm{pi}}\right)$ and aerodynamic coefficient $\left(C_{F X}\right)$ (Elshaer et al., 2017): 
$C_{\mathrm{pi}}=\frac{P_{\mathrm{i}}-P_{\mathrm{H}}}{\frac{1}{2} \rho v_{\mathrm{fH}}^{2}}$

$C_{R X}=\frac{\sum_{i=1}^{M N} E_{X i}}{1 / 2 \rho W \int_{0}^{H} U^{2} d z}$

Where, $C_{\text {pi }}$ is the average wind pressure coefficient at the $\mathrm{i}^{\mathrm{th}}$ point, $P_{\mathrm{i}}$ is the pressure at the $\mathrm{i}^{\text {th }}$ point, $P_{H}$ is the wind's static pressure at upper level of CAARC structure and $U_{H}$ is wind velocity at the upper height of the structure, equivalent to $12.7 \mathrm{~m} / \mathrm{s}$. $\rho$ is also the density of air, which is equivalent to $1.225 \mathrm{~kg} / \mathrm{m}^{3}$ (Elshaer et al., 2017).

The mean time and r.m.s. of results from the numerical and experimental data given by various researchers are compared in Table 3 . The predictions made by the current model are very similar to the experimental measurements given by Obasaju (1992) for smooth flow conditions. According to predictions made by Obasaju under smooth flow conditions as reference results, the measurements made by the analytical model show an error of about $6 \%$.

Table 3. The aerodynamic coefficients obtained by different researchers

\begin{tabular}{cccc}
\hline INLET CONDITION & \multirow{2}{*}{ CASE } & \multicolumn{2}{c}{ AERODYNAMIC COEFFICIENT } \\
\cline { 3 - 4 } & & $\mathrm{C}_{\mathrm{FX}}$ & C $\sigma_{\mathrm{Fx}}$ \\
\hline TURBULENT INFLOW & HUANG & 1.83 & 0.06 \\
\hline SMOOTH INFLOW & OBASAJO & 1.49 & 0.06 \\
\hline TURBULENT INFLOW & OBASAJO & 1.31 & 0.28 \\
\hline PRESENT WORK & & 1.39 & --- \\
\hline
\end{tabular}

The results of our study show a good correlation between the predictions made in this study for the average pressure factor and the experimental measurements carried out by other researchers. As expected, distribution of the calculated pressure in present simulation is close to the experimental predictions associated with turbulence conditions and is consistent with these logical results. In terms of correlation between the various measurements performed at $Z=\frac{2}{3} H$, when the range $0<\frac{\mathrm{X}}{\mathrm{L}}<1.5$ (related to front aspect of the building) is considered, the simulation will be very good and upward type. The same situation is observed in the range $2.5<\frac{\mathrm{X}}{\mathrm{L}}<4$, which is related to the building's back face. In the side faces where $1.5<\frac{\mathrm{X}}{\mathrm{L}}<2.5$, the dispersion of the data is more evident. At first, the simulation results are downward and $\operatorname{after} \frac{\mathrm{X}}{\mathrm{L}}=2$, they will be upward.

The r.m.s. values regarding pressure distribution obtained in this study are comparable to the measurements and results of the NPL research and Huang et al. (2007). When the front face of the building $\left(0<\frac{X v}{L}<1.5\right)$ is examined, there will be a significant difference with the results of other studies. For this face, results are somewhat correlated with the results of Zhang et al. and TJ. Similar distribution patterns can be found for all measurements performed on lateral surfaces $\left(1.5<\frac{X v}{L}<2.5\right)$. Significant differences are also observed in the results for r.m.s. values of the pressure, and the present results are somewhat upward and close to the results of University of Bristol and Ottawa (Huang et al., 2007). 

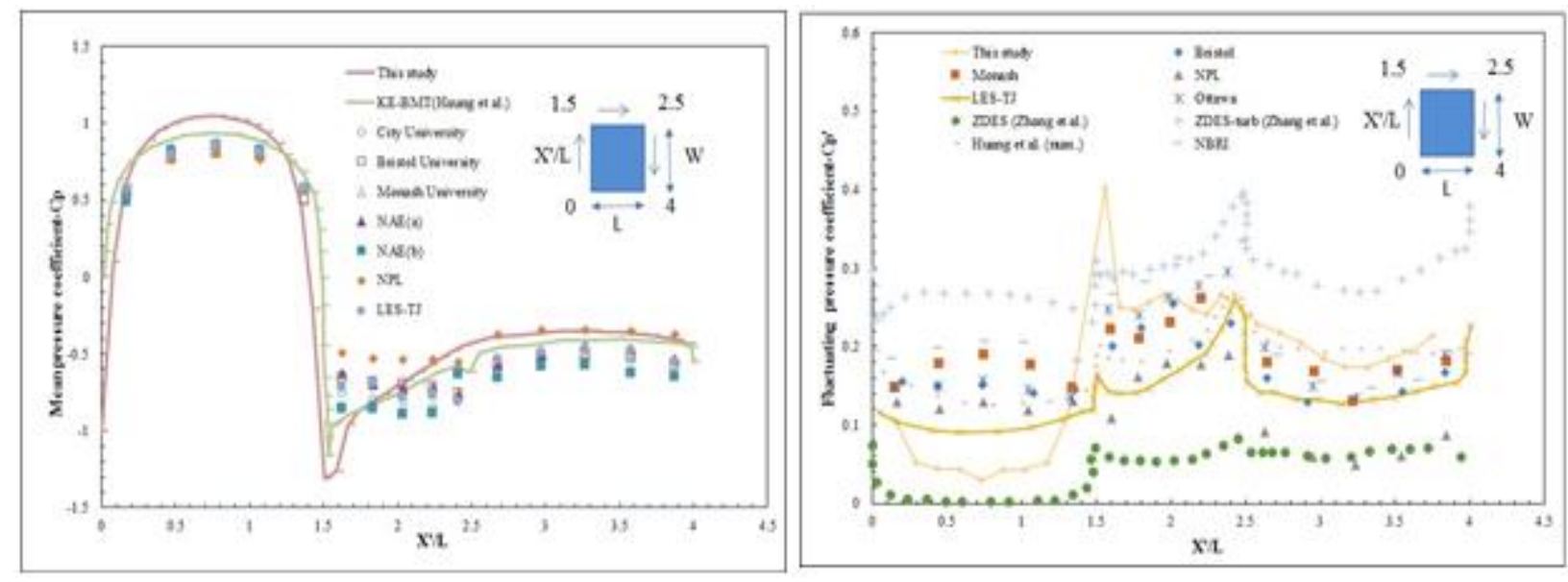

Fig 3. Medium changes of pressure coefficients and r.m.s. of pressure coefficients with the change ratio of $\frac{X t}{L}$

$$
\text { on the structure's area at the height } Z=\frac{2}{3} H
$$

\section{WIND PRESSURE ANALYSIS ON CAARC MODEL}

The contours of wind pressure coefficients distribution are depicted in Fig.4 as an important method for describing the characteristics and method of wind pressure distribution on the building. In this form of pressure and flow around the building, $(\mathrm{X}-\mathrm{Y})$ and $(\mathrm{X}-\mathrm{Z})$ are provided on horizontal and vertical plates, respectively. Additionally, 3D flow patterns are displayed in terms of the medium flow path, which is located along a vertical line at upstream of the building.

The flow field is observed nearly symmetric with two large tornadoes in the area behind the $\mathrm{X}-\mathrm{Y}$ surface at $Z=\frac{1}{3} H$. However, this property is not observed in $Z=\frac{2}{3} H$, where asymmetric tornadoes are created behind the building, as reported by Huang et al. (2007).

Figure 4 also shows the values of the average pressure coefficient obtained in this work on front and rear faces of the CAARC building model. The agreement of pressure distribution in the opposite direction to the wind is very good with the predictions obtained by Huang et al. (2007). The results are more dispersed on the back side of the wind, however, consistency of the results was seen with this work in terms of numerical values as well as the pressure contour position with existing predictions.
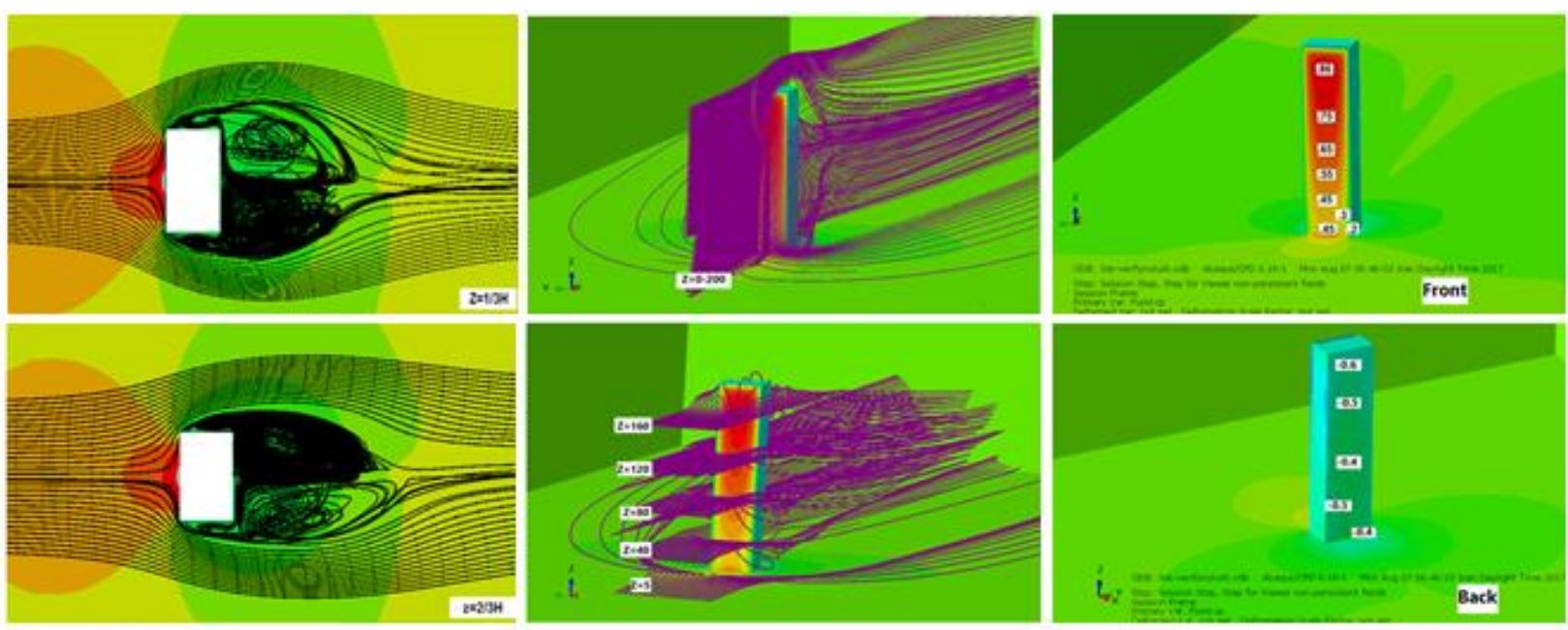

Fig 4. Medium pressure and flow lines on the CAARC building

\section{ANALYSIS FOR SENSITIVITY OF NUMERICAL RESULTS TO VARIOUS PARAMETERS}


In order to analyze the sensitivity of wind-structure interaction to the studied parameters (wind speed, structural damping and density status around the structure), numerous modeling cases were accomplished by ABAQUS. The full simulation program and the applied wind speed are presented in Table 4. In this table, each letter has a special meaning. The letter " $R$ " indicates that the fixing conditions of bearing are assumed to be constant. The letter " $D$ " represents the structural damping. The location of the structure in open ground conditions is indicated by the letter "O" and in denser areas such as urban environments, it is indicated by " $U$ ".

Table 4. The complete program for conducted simulation

\begin{tabular}{|c|c|c|c|}
\hline Case & $\begin{array}{c}\text { Structural } \\
\text { damping }\end{array}$ & $\begin{array}{c}\text { Ground } \\
\text { type }\end{array}$ & Decreased wind speed $\left(V_{H} / n W\right)$ \\
\hline RO & No & Open & $\left(V_{H} / n W\right)=2,4,6,8,10$ \\
\hline ROD & Yes & Open & $\left(V_{H} / n W\right)=2,4,6,8,10$ \\
\hline RU & No & Urban & $\left(V_{H} / n W\right)=2,4,6,8,10$ \\
\hline RUD & Yes & Urban & $\left(V_{H} / n W\right)=2,4,6,8,10$ \\
\hline
\end{tabular}

As it can be seen, the aero-elastic behavior of the CAARC building model in this work was investigated by analyzing its structural response under five wind speeds (equal to 2, 4, 6, 8 and 10) according to the reduced velocities $\left(\mathrm{V}_{\mathrm{H}} / \mathrm{nW}\right)$. Now, the effect of different parameters on structure's behavior against wind pressure will be investigated.

\section{Effects of structural damping and wind speed}

Figure 5 shows the time histories of longitudinal displacements above the building with damping and located in an open space for various wind speeds simulated in the aero-elastic analysis. The results of simulations for a structure without damping in an open space are also given in Fig. 6. As expected, longitudinal displacements domains increased with increased reduced velocity. In Fig 5, the effect of structural damping on the longitudinal reaction is shown in $\frac{V_{H}}{n W}=2$, where the aerodynamic damping is very low. For the rest of the wind velocities, the longitudinal response gradually decreases by structural damping. In lower ranges of the reduced velocity, the structural damping is much stronger than the aerodynamic damping.

Average and r.m.s. values of the structural responses obtained from time histories shown in Figures 5 and 6 were normalized with the building width and are displayed as a function of reduced speed $\frac{\mathrm{V}_{\mathrm{H}}}{\mathrm{nW}}$ in Fig. 7. In addition, the minimum and maximum values for data reported by Melbourne (1980) were also presented, suggesting a function to represent the best fit with most of the presented data.

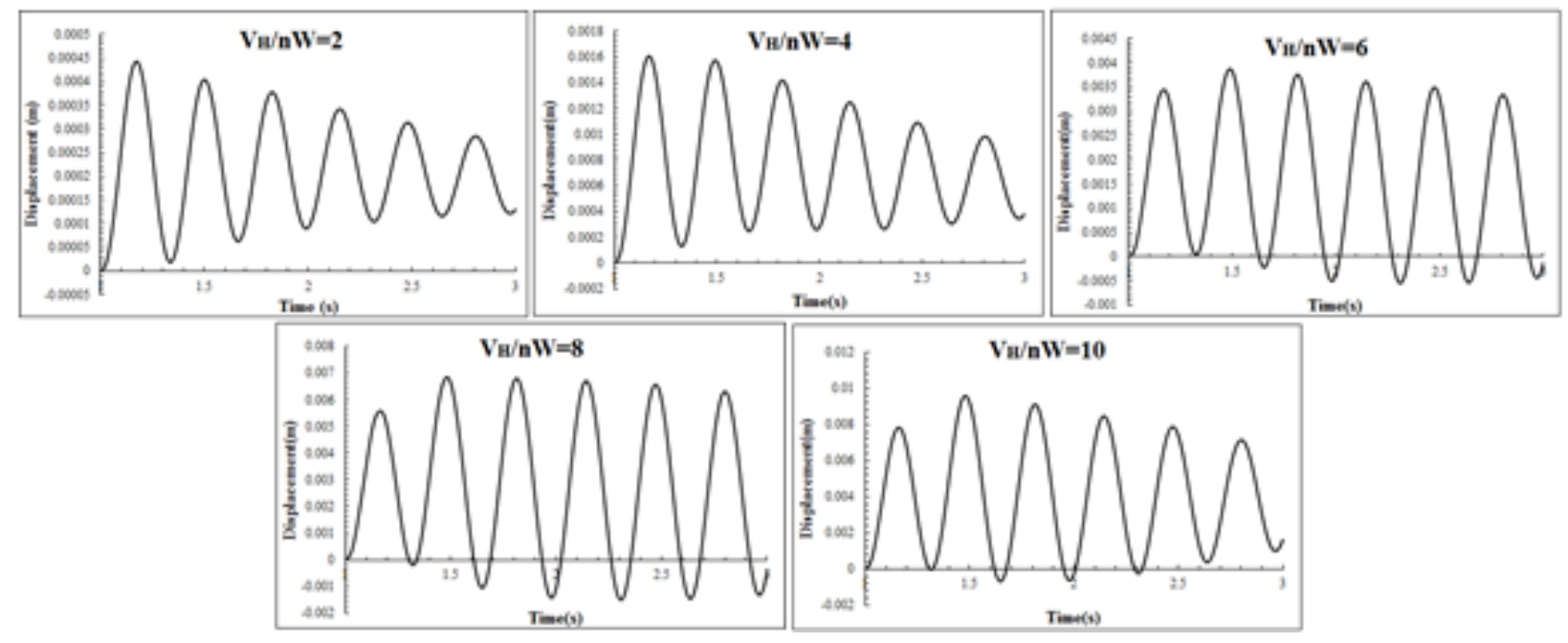

Fig 5. Time histories for longitudinal displacements above the building CAARC in the mode ROD 


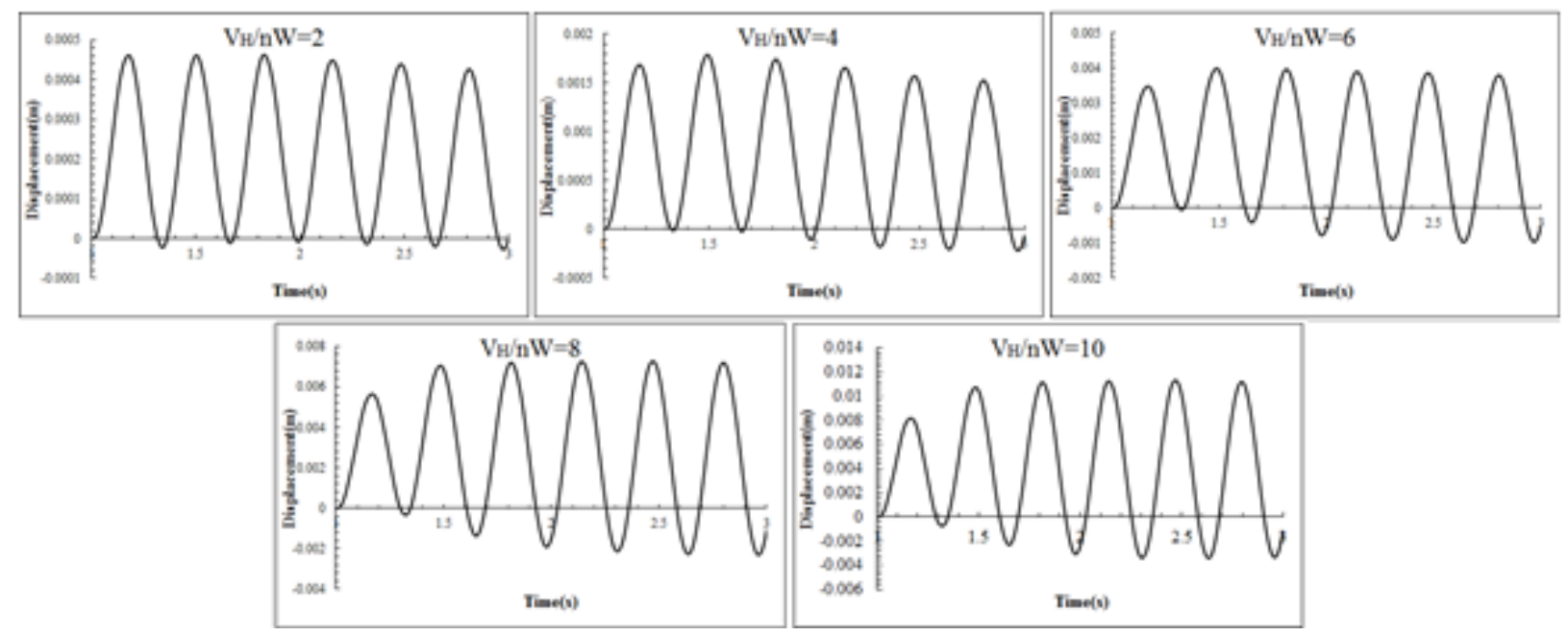

Fig 6. Time histories for longitudinal displacements above the building CAARC in the mode RO

The average normalized displacements curve along the wind $(\overline{\mathrm{x}} / \mathrm{L})$ which was obtained in this work, has a very suitable consistency with the predictions presented by Thepmongkron et al. (1999) for structures with and without damping. The agreement between current results and the proposed function by Melbourne (1980) is also significant, although the curve derived from the current simulation is slightly higher than the function proposed by Melbourne (1980).

Curve for r.m.s. values of normalized displacements of the longitudinal wind $\left(\sigma_{x} / L\right)$ obtained in the present analysis represent a reasonable correlation with the predictions made by Braun and Awruch (2009) for structures with damping. In addition, the results of the analytical measurements carried out in our research begin a higher deviation from Braun and Awruch's data at $\frac{V_{H}}{n W}=5$. It is also seen that predictions for r.m.s. of the displacements along the wind in this study are higher than the distribution range of data reported by Melbourne (1980). The curve proposed by Melbourne (1980) for the $\sigma_{x} / \mathrm{L}$ data is unreal, since today it is well known that r.m.s. of the response varies to a power less than three in the low reduced velocity and varies to a power higher than three in the higher reduced velocities. On the other hand, the average variation in response with the square of wind speed, as proposed by Melbourne (1980), is quite reasonable.

All simulations performed without structural damping caused a significant increase in r.m.s. of response along the longitudinal wind. According to Melbourne (1980), the experimental results show the structural response dependence on the critical damping ratio with negative power, confirming the results of this work regarding the structural damping effect on the building displacement (Melbourne, 1980). 


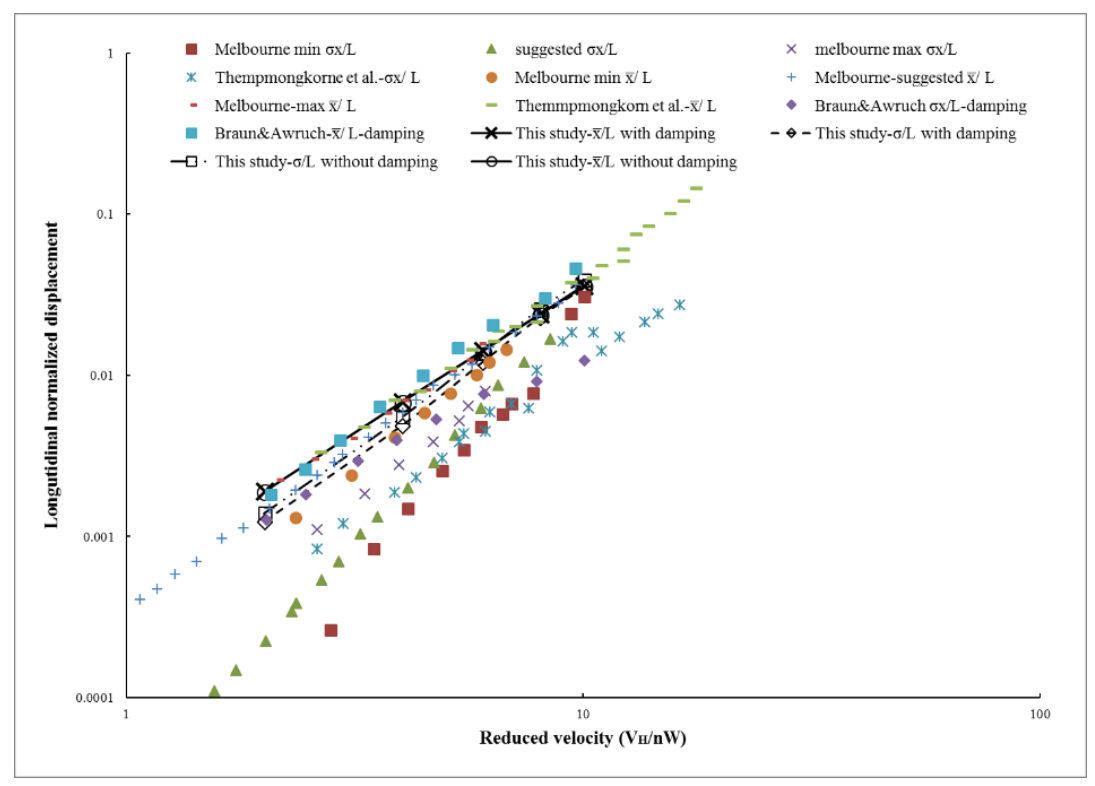

Fig 7. Normalized longitudinal displacements as a function of reduced velocity

\section{Impact of the ground conditions}

Figures 8 and 9 depict the time histories for the displacement of the structural upper point calculated along the wind (Ux) for two structures located in the urban environment, one without damping (RU) and the other with a damping (RUD). Also, Tables 5 and 6 present results of all numerical simulations conducted in terms of displacements above the building $\left(\overline{\mathrm{u}}_{\mathrm{x}},\left|\mathrm{u}_{\mathrm{x}}\right|_{\max }\right)$ and forces and anchors in the building foundation $\left(\left|\mathrm{H}_{\mathrm{x}}\right|_{\max } \quad\right.$ : $\left.\left|\mathrm{M}_{\mathrm{y}}\right|_{\max }\right)$.

For the two wind load conditions (one in open space and one in urban environment), wind speed is constant at high height $(12.7 \mathrm{~m} / \mathrm{s})$, however, the wind speed (or velocity) profile at the building height is different due to different environmental roughness.

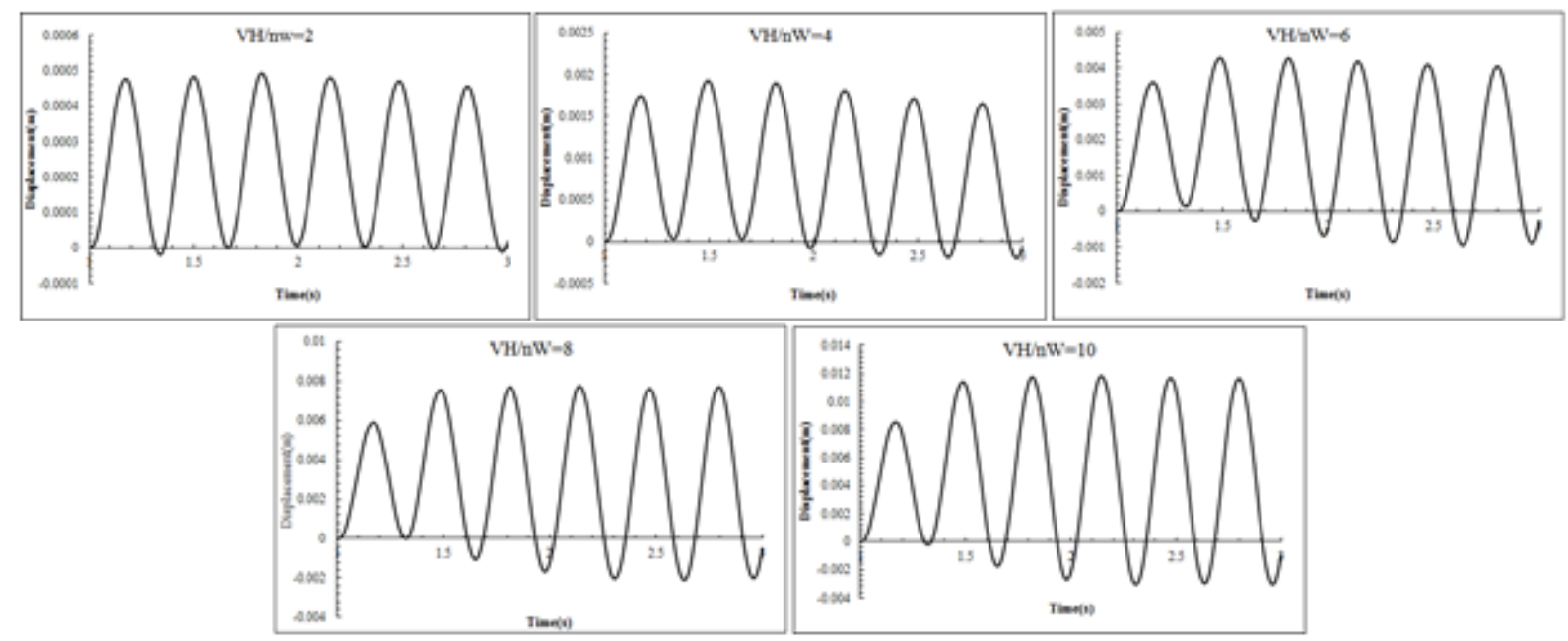

Fig 8. Time histories for longitudinal displacement above the CAARC building in the mode RU 


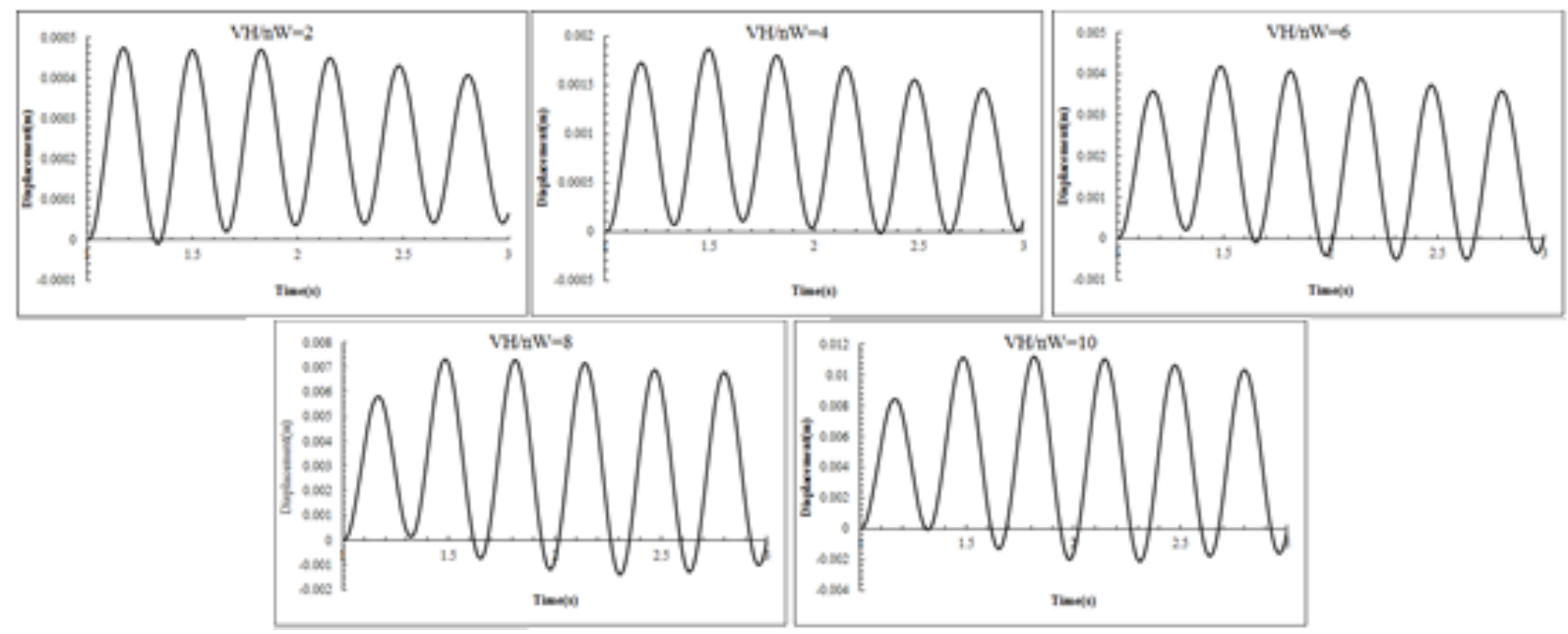

Fig 9. Time histories for longitudinal displacement above the CAARC building in the mode RUD

The review of Tables 5 and 6 shows that the response in urban areas is generally larger than that found in open lands. The reason for this can be stated that, in urban conditions, due to the appearance of wind tunnels around the structure, which is caused by the layout of obstacles and surrounding buildings, the wind speed in the whole height of the building is increased and as a result, the pressure resulted from the wind increases. For this reason, in all cases shown in Table 5, the average longitudinal wind transfer in urban environments is always larger than the corresponding displacements in open space. Also, in all cases shown at Table 6, the maximum internal forces established at the building foundation are always larger in urban environments compared to the corresponding displacements in open spaces.

In addition, Table 5 shows the maximum standard deviation in a longitudinal wind $\left(\sigma_{\mathrm{x}, \max }\right)$ above the building for conditions of open space and urban environments. The maximum standard deviations of upper displacements in urban environments are higher than those achieved in open spaces. This result is due to the high wind turbulence occurring in urban areas, which prevents the formation of a regular whirlwind.

Table 5. Mean, maximum and standard deviation values for horizontal displacements above the building

\begin{tabular}{cccc}
\hline Case & $\overline{\boldsymbol{u}}_{\boldsymbol{x}}(\boldsymbol{m})$ & $\left|\boldsymbol{u}_{x}\right| \max (\boldsymbol{m})$ & $\boldsymbol{\sigma}_{\boldsymbol{x}, \boldsymbol{m a x}}(\boldsymbol{m})$ \\
$R O$ & $3.92 \times 10^{-3}$ & $11.30 \times 10^{-3}$ & $4.74 \times 10^{-3}$ \\
$R O D$ & $4.01 \times 10^{-3}$ & $9.60 \times 10^{-3}$ & $3.04 \times 10^{-3}$ \\
$R U$ & $4.38 \times 10^{-3}$ & $11.90 \times 10^{-3}$ & $4.81 \times 10^{-3}$ \\
$R U D$ & $4.41 \times 10^{-3}$ & $11.20 \times 10^{-3}$ & $4.27 \times 10^{-3}$ \\
\hline
\end{tabular}

Table 6. Maximum internal forces at the building foundation

\begin{tabular}{ccc}
\hline Case & $\left|\boldsymbol{H}_{\boldsymbol{x}}\right|_{\max }(\boldsymbol{k N})$ & $\left|\boldsymbol{M}_{\boldsymbol{y}}\right|_{\max }(\boldsymbol{k N \boldsymbol { N }})$ \\
$R O$ & -26.1523 & 2.55 \\
$R O D$ & -26.1523 & 2.40 \\
$R U$ & -26.1523 & 2.55 \\
$R U D$ & -26.1523 & 2.40 \\
\hline
\end{tabular}

\section{CONCLUSION}

In this research, several 3D models of the CAARC's sample was modelled using ABAQUS software and their nonlinear analysis was accomplished under the influence of wind load. The results show: 
1) In the structures with damping, the range of longitudinal displacements increases with increased velocity.

2) In the structures with damping, longitudinal displacements are gradually reduced by structural damping.

3) The structural damping effect in the lower speed ranges is much stronger than the aerodynamic damping effect.

4) The amplitude and magnitude of responses in the structures with damping are much larger compared to those for the structures with damping.

5) Major fluctuations in wind direction occur at low speeds. As wind speed increases, most displacements are guided in the transverse direction.

6) The density or lack of density among buildings around the structure under consideration will definitely change the wind speed profile at the building's height. If the density is high around the building, by creating wind tunnels, the wind will affect with higher speed on the building height, resulting in the increased maximum stresses and displacements that occur in the lower and upper parts of the structure.

7) The construction model used in this study (solid elastic body) is very different from construction models commonly used in wind tunnel experiments. A building model with a hollow section and hardeners can be analyzed with conditions that are used in wind tunnel models. Additionally, an algorithm for generating random fluctuations on the average velocity profile should be applied to simulate atmospheric turbulence conditions in the wind. Turbulent fluctuations were not applied in boundary conditions used in this study.

\section{ACKNOWLEDGEMENT}

The authors thank Amir Kabir University and Mohaghegh Ardabili University for providing supercomputer resources. In addition, the authors of this article are grateful to all the scientific members of this publication.

\section{REFERENCES}

1. ABAQUS User's Manual, V. 6.16.1.

2. Abdi, S.D., Bitsuamlak, G.T. 2016. Wind flow simulations in idealized and real built environments with models of various level of complexity, Wind and Structures Journal, 22, 503-524.

3. Alminhanaa, G.W., Brauna, A.L., Souzaa, A.M.L. 2018. A numerical study on the aerodynamic performance of building cross sections using corner modifications, Latin American Journal of Solis and Structures. 15, 1-18.

4. Cao, S., Tamura, Y., Kikuchi, N., Saito, M., Nakayama, I., Matsuzaki, Y. 2009. Wind characteristics of a strong typhoon, J. Wind Eng. Ind. Aerodyn, 97, 11-21.

5. Chakraborty, S., Dalui, S.K., Ahuja, A.K. 2014. Wind load on irregular plan shaped tall building - a case study, Wind and Structures Journal, 19, 59-73.

6. Elshaer, A., Bitsuamlak, G., El Damatty, A. 2017. Enhancing wind performance of tall buildings using corner aerodynamic optimization, Eng. Struct. 136,133-148.

7. Elshaer, A., Gairola, A., Adamek, K., Bitsuamlak, G. 2017. Variations in wind load on tall buildings due to urban development, Sustain. Cities Soc, 34, 264-277.

8. Felippa, C.A., Park, K.C., Farhat, C. 2001. Partitioned analysis of coupled mechanical systems, Computer Methods in Applied Mechanics and Engineering Journal, 190, 3247-3270.

9. Hanson, T., Summers, D., Wilson, C.B. 1986. A three-dimensional simulation of wind flow around buildings, International Journal for Numerical Methods in Fluids, 6,113-127.

10. Hirt, C.W., Ramshaw, J.D., Stein, L.R.1978. Numerical simulation of three-dimensional flow past bluff bodies, Computer Methods in Applied Mechanics and Engineering Journal, 14, 93-124.

11. Huang, M. 2017. Peak Distributions and Peak Factors of Wind-induced Pressure Processes on Tall Buildings, High-Rise Buildings Under Multi-Hazard Environment, Springer, Singapore, pp. 83-104.

12. Huang, S., Li, Q.S., Xu, S. 2007. Numerical evaluation of wind effects on a tall steel building by CFD, J. Constr. Steel Res, 63, 612-627.

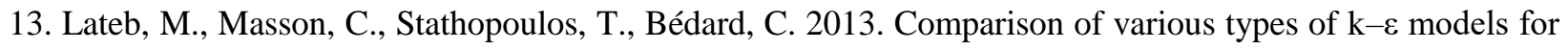
pollutant emissions around a two-building configuration, Journal of Wind Engineering and Industrial Aerodynamic, 115, 9-21.

14. Melbourne, W.H. 1980. Comparison of measurements on the CAARC standard tall building model in simulated model wind flows, J. Wind Eng. Ind. Aerodynamic, 6, 73-88. 
15. Meng, F.Q., He, B.J., Zhu, J., Zhao, D.X., Darko, A., Zhao, Z.Q. 2018. Sensitivity analysis of wind pressure coefficients on CAARC standard tall buildings in CFD simulations, Journal of Building Engineering, $16,146-158$.

16. Montazeri, H., Blocken, B. 2013. CFD simulation of wind-induced pressure coefficients on buildings with and without balconies: validation and sensitivity analysis, Build. Environ, 60, 137-149.

17. Mou, B., He, B.J., Zhao, D.X., Chau, K.W. 2017. Numerical simulation of the effects of building dimensional variation on wind pressure distribution, Eng. Appl. Comput. Fluid Mech, 11,293-309.

18. N. Lin, Y., Letchford, C., Tamura, Y., Liang, B., Nakamura, O. 2005. Characteristics of wind forces acting on tall buildings, J. Wind Eng. Ind. Aerodyn, 93, 217-242.

19. Obasaju, E.D. 1992. Measurement of forces and base overturning moments on the CAARC tall building model in a simulated atmospheric boundary layer, Journal of Wind Engineering and Industrial Aerodynamics, $40,103-26$.

20. Smagorinsky, J. 1963. General circulation experiments with primitive equations I, the basic experiment, Mon Weather Rev, 91, 99-165.

21. Summers, D.M., Hanson, T., Wilson, C.B. 1986. Validation of a computer simulation of wind flow over a building model, Building Environment Journal, 21, 97-111.

22. Tominaga, Y., Mochida, A., Yoshie, R., Kataoka, H., Nozu, T., Yoshikawa, M., Shirasawa, T. 2008. AIJ guidelines for practical applications of CFD to pedestrian wind environment around buildings, J. Wind Eng. Ind. Aerodyn, 96,1749-1761.

23. Wardlaw, R.L., Moss, G.F. 1970. A standard tall building model for the comparison of simulated natural winds in wind tunnels, CAARC, C.C.662m Tech.

24. Yousef, M.A.A., Selvam, P.R., Prakash, J. 2018. A comparison of the forces on dome and prism for straight and tornadic wind using CFD model, Wind and Structures Journal, 26, 369-382.

25. Zhang, Q., Hisada, T. 2004. Studies of the strong coupling and weak coupling methods in FSI analysis, International Journal for Numerical Methods in Engineering, 60, 2013-2029.

26. Zhao, Z.Q., He, B.J., Li, L.G., Wang, H.B., Darko, A. 2017. Profile and concentric zonal analysis of relationships between land use/land cover and land surface temperature: case study of Shenyang, China, Energy Build, 155, 282-295. 